\title{
CINÉTICA DA FERMENTAÇÃO ALCOÓLICA NA ELABORAÇÃO DE VINHO DE MELANCIA
}

\author{
RAFAEL DA COSTA ILHÉU FONTAN* \\ LIZZY AYRA ALCÂNTARA VERÍSSIMO** \\ WILLIAN SOARES SILVA*** \\ RENATA CRISTINA FERREIRA BONOMO**** \\ CRISTIANE MARTINS VELOSO*****
}

\begin{abstract}
O objetivo deste trabalho foi produzir bebida fermentada de melancia, comparar sua composição com padrões existentes na legislação e determinar alguns parâmetros cinéticos da fermentação. O processo foi realizado em batelada a $28 \pm 0,1^{\circ} \mathrm{C}$ durante 20 dias. $\mathrm{O}$ produto final obtido apresentou $\mathrm{pH}$, acidez total, teor de sólidos solúveis, teor alcoólico e de compostos fenólicos totais (respectivamente 4,1; 4,45 g/L; 6,0 $0^{\circ}$ Brix; $10 \%$ v/v e $677,73 \mathrm{mg} / \mathrm{L}$ ) de acordo com a legislação brasileira em vigor e valores similares ao reportado na literatura para outros fermentados. O estudo cinético mostrou que após $48 \mathrm{~h}$ não ocorreram variações nas concentrações de substrato, produto e biomassa, (respectivamente $62,2 \mathrm{~g} / \mathrm{L}, 79,4 \mathrm{~g} / \mathrm{L}$ e $20,0 \mathrm{~g} / \mathrm{L}$ ). Alcançou-se rendimento de $94 \%$ e produtividade nas primeiras $48 \mathrm{~h}$ de $1,65 \mathrm{~g} / \mathrm{L} \cdot \mathrm{h}$. O rendimento em produto $\left(Y_{p / S}\right)$ foi de 0,65 , o fator de conversão de substrato em biomassa $\left(Y_{x / S}\right)$ de 0,14 e a velocidade específica de crescimento igual a $0,028 \mathrm{~h}^{-1}$. A produção do fermentado de melancia apresentou-se tecnicamente viável, contudo, mais estudos em relação aos aspectos sensoriais e de conservação são necessários para garantir a segurança do produto.
\end{abstract}

PALAVRAS-CHAVE: VINHO DE MELANCIA; FERMENTAÇÃO ALCOÓLICA; COMPOSTOS FENÓLICOS.

\footnotetext{
* Doutorando em Ciência e Tecnologia de Alimentos, Professor Assistente, Departamento de Tecnologia Rural e Animal (DTRA), Universidade Estadual do Sudoeste da Bahia (UESB), Itapetinga, BA (e-mail: rafaelfontan@yahoo.com.br).

** Doutoranda em Ciência e Tecnologia de Alimentos, Universidade Federal de Viçosa, Bolsista CNPq, Viçosa, MG (e-mail: lizzy.alcantara@gmail.com).

*** Mestrando em Engenharia de Alimentos, UESB, Itapetinga, BA (e-mail: william_engenheiro@hotmail.com).

**** Doutora em Ciência e Tecnologia de Alimentos, Professora Titular, DTRA/UESB, Pesquisadora Nível 2 do CNPq, Itapetinga, BA (e-mail: bonomorcf@pq.cnpq.br).

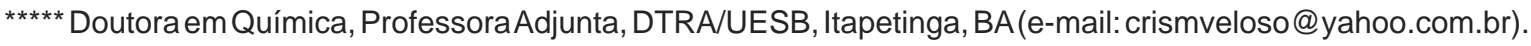




\section{INTRODUÇÃO}

O Brasil destaca-se entre os países com maior produção mundial de frutas. Contudo, o desperdício pós-colheita de algumas culturas gera prejuízos (GOMES, 2007). Assim, existe a necessidade de se desenvolver processos biotecnológicos que permitam a redução das perdas pós-colheita e que ao mesmo tempo proporcionem incremento na renda do produtor rural (DIAS, SCHAWN e LIMA, 2003; GOMES, 2007). A utilização de sucos de frutas para elaboração de bebidas fermentadas representa alternativa de aproveitamento dos frutos, evitando desperdícios e agregando valor aos mesmos.

Tradicionalmente, os vinhos são obtidos da fermentação alcoólica do mosto de uvas. Porém, vem sendo reportados na literatura diversos trabalhos sobre a preparação e caracterização de fermentados alcoólicos de outras frutas como, por exemplo, maçã (JOSHI e BHUTANI, 1991; JOSHI et al., 1991), manga (REDDY e REDDY, 2005), laranja (CORAZZA, RODRIGUES e NOZAKI, 2001), ata, siriguela e mangaba (MUNIZ et al., 2002), jabuticaba (ASQUIERI et al., 2004), cajá (DIAS, SCHAWN e LIMA, 2003) e kiwi (BORTOLINI, SANT'ANNA e TORRES, 2001) com a finalidade de produzir vinhos.

O processo de fermentação alcoólica resulta da transformação de açúcares solúveis em etanol. Entre as leveduras empregadas para tal, a Saccharomyces cerevisiae se destaca, sendo muito usada em panificação, cervejaria e destilaria, entre outros. Para produzir álcool etílico, o mosto (líquido açucarado apto a fermentar) deverá ter certa concentração de açúcares (16 a 20Brix) e componentes nutritivos (GAVA, 1984).

De acordo com a legislação brasileira vigente, fermentado de fruta é a bebida com graduação alcoólica de quatro a quatorze por cento em volume, a vinte graus Celsius, obtida pela fermentação alcoólica do mosto de fruta sã, fresca e madura de uma única espécie, do respectivo suco integral ou concentrado, ou polpa, que poderá nesses casos, ser adicionado de água. Vinhos que não são provenientes da uva devem obrigatoriamente ser rotulados com a denominação fermentado (vinho) acompanhada do nome do fruto do qual se originou (BRASIL, 1997; BRASIL, 2009).

A melancia (Citrullus lanatus), fruta que contém em torno de 10\% de sólidos solúveis, mostra-se potencialmente apta a ser submetida ao processo de transformação vinícola. A fruta, pertencente à família das cucurbitáceas, apresenta-se promissora em razão de sua produção no ano de 2010, que ultrapassou 2,05 milhões de toneladas, sendo a Bahia o maior estado produtor, com cerca de 338 mil toneladas colhidas (IBGE, 2010).

O objetivo deste trabalho foi elaborar produto fermentado de melancia, avaliando-se a cinética de fermentação alcoólica e as características físico-químicas do produto, visando à comparação com os limites legais brasileiros para bebidas alcoólicas.

\section{MATERIAL E MÉTODOS}

\subsection{MATERIAL}

O experimento de produção da bebida fermentada de melancia foi conduzido no Laboratório de Engenharia de Processos da Universidade Estadual do Sudoeste da Bahia (UESB). Para tanto, foram adquiridos na feira livre da cidade de Itapetinga (BA) frutos inteiros, sadios e no estágio ideal de maturação, selecionados com base em características visuais, de textura e aroma. Água destilada e reagentes químicos grau analítico foram empregados no experimento.

\subsection{ELABORAÇÃO DA BEBIDA FERMENTADA}

Os frutos foram imersos em solução de hipoclorito de sódio com concentração igual a $20 \mathrm{mg} / \mathrm{L}$ durante 15 minutos, e submetidos à nova lavagem em água corrente visando eliminar 
os resíduos de cloro. Depois de cortados, a polpa e as sementes foram separadas manualmente. Utilizou-se liquidificador industrial para homogeneização da polpa, que foi filtrada em coador plástico com malha de 1,0 mm, obtendo-se o volume total de $15 \mathrm{~L}$ de suco.

O suco extraído da melancia sofreu processo de sulfitação, utilizando-se metabissulfito de sódio $\left(\mathrm{Na}_{2} \mathrm{~S}_{2} \mathrm{O}_{5}\right)$ na proporção de $0,175 \mathrm{~g}$ para cada litro de suco. Manteve-se o suco em repouso por 2 horas, o qual foi novamente filtrado e teve o $\mathrm{pH}$ corrigido para 4,4 com ácido tartárico. Determinouse o teor de sólidos solúveis do mosto em refratômetro portátil, sendo a chaptalização realizada com a adição de sacarose em quantidade suficiente para se atingir teor de sólidos solúveis igual a $18^{\circ}$ Brix. Posteriormente, o mosto padronizado foi submetido a tratamento térmico a $65^{\circ} \mathrm{C}$ por 20 minutos e resfriado à temperatura ambiente.

Como inóculo utilizou-se fermento biológico liofilizado comercial (marca Dona Benta), constituído da levedura Saccharomyces cerevisae. O pé de cuba foi preparado com $10 \%$ do volume total e concentração inicial de $3,7 \mathrm{~g} / \mathrm{L}$ de fermento, mantido a $28^{\circ} \mathrm{C}$ por $24 \mathrm{~h}$. Uma vez inoculado o fermento, o mosto foi dividido em dois reatores em batelada, dotados de batoque hidráulico para saída do dióxido de carbono produzido durante a fermentação, evitando contaminação pelo ar exterior. Os reatores foram mantidos em temperatura constante de $28,0 \pm 0,1^{\circ} \mathrm{C}$, em estufa bacteriológica (BOD) durante 20 dias.

Terminada a etapa de fermentação alcoólica, realizou-se a clarificação do produto obtido com gelatina incolor e sem sabor (marca Royal) na concentração de 3,0 g/L (CORAZZA, RODRIGUES e NOZAKI, 2001; TORRES NETO et al., 2006). Nessa etapa ocorre a remoção das partículas sólidas em suspensão, que podem originar produtos com odor desagradável, como $\mathrm{H}_{2} \mathrm{~S}$ ou mercaptana, que depreciam o vinho (BORZANI, LIMA e AQUARONE, 1983). O fermentado foi filtrado, submetido a novo tratamento térmico a $65^{\circ} \mathrm{C}$ por 20 minutos, resfriado, envasado em frascos de vidro sanitizados e armazenado à temperatura ambiente.

\subsection{ANÁLISES FÍSICO-QUÍMICAS}

O suco de melancia foi analisado quanto ao $\mathrm{pH}$, teor de sólidos solúveis e densidade. $\mathrm{Na}$ bebida fermentada obtida, além dessas análises foram determinados acidez total, acidez volátil, acidez fixa (todas expressas em $\mathrm{g} / \mathrm{L}$ de ácido cítrico) e teor de compostos fenólicos totais (expresso $\mathrm{em} \mathrm{mg} / \mathrm{L}$ de ácido gálico). Todas as análises foram realizadas segundo as Normas Analíticas do Instituto Adolfo Lutz (2008), à exceção do teor de compostos fenólicos totais, determinado pelo método modificado do reagente Folin-Ciocalteau (USENIK, FABCIC e STAMPAR, 2008), utilizandose como padrão o ácido gálico.

\subsection{CINÉTICA DE CRESCIMENTO CELULAR, DE FORMAÇÃO DE PRODUTO E CONSUMO DE SUBSTRATO}

Periodicamente, alíquotas do mosto em fermentação foram retiradas e determinadas a concentração celular, a concentração de sacarose e seu teor alcoólico. Tais determinações foram realizadas em intervalos de 1 hora nas primeiras 27 horas do processo, aumentando-se esse intervalo até o final da fermentação.

A concentração de células no mosto em fermentação foi determinada a partir da densidade ótica do mesmo, medindo-se o valor da absorbância no comprimento de onda de $640 \mathrm{~nm}$ em espectrofotômetro digital. Obteve-se curva analítica, relacionando a concentração celular (expressa em g/L) em função da absorbância.

Para se estimar a concentração de sacarose no mosto, inicialmente foi determinado o teor de sólidos solúveis (TSS), expresso em ${ }^{\circ}$ Brix, utilizando-se refratômetro portátil. A partir dos resultados do TSS, a concentração de sacarose, expressa em $\mathrm{g} / \mathrm{L}$, foi estimada utilizando-se a Equação 1 (TORRES NETO et al., 2006): 
Para conhecer a concentração de etanol no mosto, primeiro determinou-se a densidade relativa do fermentado em densímetro, o qual foi mergulhando em aproximadamente $40 \mathrm{~mL}$ da amostra. Os resultados obtidos diretamente da leitura na escala graduada do equipamento foram corrigidos para a temperatura de $28^{\circ} \mathrm{C}$ por meio de tabelas (PELTER e MCQUADE, 2005) e a concentração de etanol, expressa em ${ }^{\circ} \mathrm{GL}$, calculada a partir da Equação 2 (OURA, 1977):

$$
\text { álcool }\left({ }^{\circ} G L\right)=\left(D_{i}-D_{x}\right) \times 125
$$

Em que:

$D_{i}$ e $D_{x}$ são, respectivamente, a densidade relativa no momento em que a fermentação se inicia e no momento em que se deseja obter o teor alcoólico.

A concentração de etanol foi convertida para $\mathrm{g} \cdot \mathrm{L}^{-1}$ para os cálculos de rendimento e produtividade.

\subsection{RENDIMENTO, PRODUTIVIDADE E PARÂMETROS CINÉTICOS DA FERMENTAÇÃO ALCOÓLICA}

O rendimento $(R)$ da fermentação alcoólica, expresso em \%, fornece em valores quantitativos a eficácia com que as leveduras convertem sacarose em etanol. O rendimento (expresso em \%) e a produtividade $(\operatorname{Pr})$ (expressa em $\mathrm{g} / \mathrm{L} \cdot \mathrm{h}$ ) para o processo de produção foram calculados utilizando-se as Equações 3 e 4 (LOPES e SILVA, 2006):

$$
\begin{gathered}
R=\frac{P_{\text {EXP }}}{P_{\text {TEO }}} \times 100 \\
\operatorname{Pr}=\frac{P_{\text {EXP }}}{t}
\end{gathered}
$$

Em que:

$P_{\text {EXP }}=$ concentração $(\mathrm{g} / \mathrm{L})$ de etanol experimental,

$P_{\text {TEO }}=$ concentração $(\mathrm{g} / \mathrm{L}$ ) de etanol máxima teórica (estequiométrica), e

$t=$ tempo de fermentação $(\mathrm{h})$.

$O$ rendimento em produto $\left(Y_{P / S}\right)$ e o fator de conversão de substrato em biomassa $\left(Y_{x / S}\right)$ foram calculados por meio das Equações 5 e 6 (ALMEIDA et al., 2006; STROPPA et al., 2009):

$$
\begin{gathered}
Y_{P, S}=\frac{P_{f}-P_{0}}{S_{0}-S_{f}} \\
Y_{X / S}=\frac{X_{f}-X_{0}}{S_{0}-S_{f}}
\end{gathered}
$$

Em que:

$P_{0}$ e $P_{f}=$ concentrações $(\mathrm{g} / \mathrm{L})$ inicial e final do etanol;

$X_{f}$ e $X_{0}=$ as concentrações $(\mathrm{g} / \mathrm{L})$ inicial e final de células, e

$S_{0}, S_{f}=$ as concentrações $\left(g \cdot \mathrm{L}^{-1}\right)$ inicial e final de sacarose, respectivamente.

\subsection{VELOCIDADE ESPECÍFICA DE CRESCIMENTO CELULAR}

Durante a fase exponencial de crescimento celular no processo fermentativo, a taxa de 
crescimento é proporcional à concentração celular. Admitindo-se que nessa fase a velocidade específica de crescimento celular é constante, ela pode ser determinada a partir da Equação 7 (STROPPA et al., 2009):

$$
\frac{d X}{d t}=\mu X \Rightarrow \ln X=\ln X_{0}+\mu \cdot t
$$

Em que:

$\mu=$ velocidade específica de crescimento $\left(\mathrm{h}^{-1}\right)$.

\section{RESULTADOS E DISCUSSÃO}

\subsection{CARACTERIZAÇÃO FÍSICO-QUÍMICA}

O suco de melancia utilizado para a fermentação apresentou teor de sólidos solúveis de $9{ }^{\circ}$ Brix, pH igual a 5,2 e densidade de $1070 \mathrm{~kg} / \mathrm{m}^{3}$. Na Tabela 1 são apresentados os resultados de parte das análises físico-químicas do fermentado de melancia, comparados aos obtidos para os produtos fermentados de outras frutas. Verificou-se que os parâmetros avaliados do fermentado de melancia não diferem consideravelmente dos fermentados de outras frutas. $O$ produto apresentou teor alcoólico em etanol de $10 \% \mathrm{v} / \mathrm{v}$ a $20^{\circ} \mathrm{C}$. A acidez total do fermentado, expressa em ácido cítrico, foi de $4,45 \mathrm{~g} / \mathrm{L}$, enquadrando-se nos limites da legislação vigente para acidez total, entre 3,3 a 7,8 g/L (BRASIL, 2009). Os valores obtidos para a acidez fixa e volátil, expressos em ácido cítrico, foram iguais a $4,2 \mathrm{~g} / \mathrm{L}$ e $0,25 \mathrm{~g} / \mathrm{L}$, respectivamente, também em conformidade com a legislação brasileira (RIZZON, MANFROI e MENEGUZZO,1998)

TABELA 1 - COMPARAÇÃO DA COMPOSIÇÃO DO FERMENTADO DE MELANCIA COM FERMENTADOS DE OUTRAS FRUTAS

\begin{tabular}{llccccc}
\hline Fruta & & $\mathbf{p H}$ & $\begin{array}{c}\text { Acidez } \\
\text { total } \\
(\mathbf{g} / \mathbf{L})\end{array}$ & $\begin{array}{c}\text { TSS } \\
\left({ }^{\circ} \text { Brix) }\right.\end{array}$ & $\begin{array}{c}\text { Etanol } \\
(\% \text { v/v) }\end{array}$ & Referência \\
\hline Melancia & & 4,1 & 4,45 & 6,0 & 10,0 & -- \\
Figo-da-Índia & (fruto) & 3,3 & 4,5 & 2,02 & 6,1 & Lopes e Silva,2006 \\
& (polpa) & 4,0 & 5,0 & 3,62 & 5,5 & $\begin{array}{c}\text { Corazza, Rodrigues e } \\
\text { Laranja }\end{array}$ \\
Jabuticaba & & 3,3 & 8,1 & 8,0 & 10,6 & Nozaki, 2001 \\
Cajá & (polpa) & 4,0 & 3,3 & 3,9 & 10,0 & Asquieri et al., 2004 \\
& (casca) & 3,3 & 7,8 & 8,7 & 13,0 & Dias, Schawn e Lima, \\
\hline
\end{tabular}

Um dos principais fatores da qualidade dos vinhos consiste na sua composição fenólica. Dos compostos fenólicos com baixa massa molecular encontrados em vinhos, a catequina, a epicatequina, a procianidina B2, B3 e B4, a quercetina e o ácido gálico são predominantes (SHAHIDI e NACZK, 1995).

O teor de compostos fenólicos totais presentes no fermentado de melancia foi de $677,73 \mathrm{mg} / \mathrm{L}$, expresso em acido gálico. Embora inferior aos teores encontrados em vinho tinto, que variam de 1000 a $4000 \mathrm{mg} / \mathrm{L}$, mostrou-se superior ao resultado médio de vinho branco, aproximadamente $250 \mathrm{mg} / \mathrm{L}$ de compostos fenólicos (SHAHIDI e NACZK, 1995).

O produto obtido apresentou características similares às de fermentados de outras frutas de acordo com os padrões legais vigentes. No entanto, para verificar sua aceitação no mercado, mais estudos são necessários para determinar suas características sensoriais e de conservação, entre outras. 


\subsection{CINÉTICA DA FERMENTAÇÃO ALCOÓLICA}

Na Figura 1 são apresentados os perfis de consumo de substrato $(S)$, crescimento celular $(X)$ e produção de etanol $(P)$, todos expressos em g/L, em função do tempo de fermentação. Verificouse a estabilização das concentrações de substrato, produto e de biomassa em torno de 48 horas de fermentação, com valores respectivamente de 62,2 g/L, 79,4 g/L e 20,0 g/L. A estabilização do teor de açucares é consequência da existência de compostos não fermentáveis no meio (AQUARONE et al., 2001).

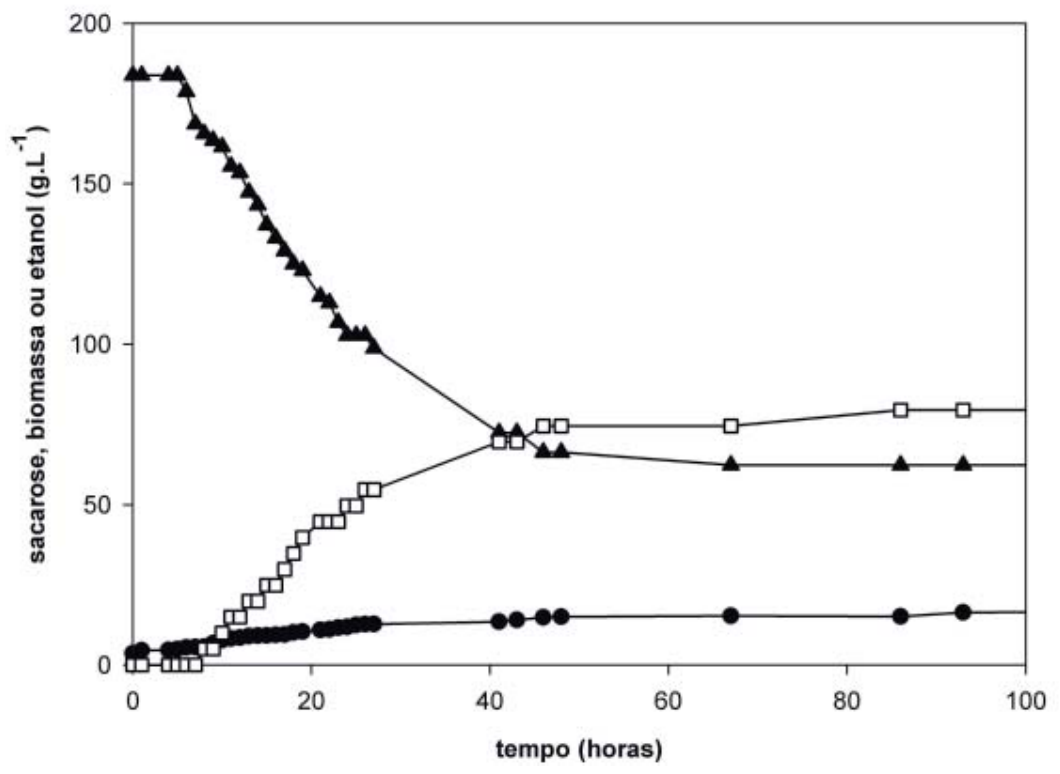

FIGURA 1 - PERFIL CINÉTICO DA PRODUÇÃO DO FERMENTADO DE MELANCIA Nota: CONCENTRAÇÃO CELULAR OU DE BIOMASSA (•), DE SACAROSE (ム) E DE ETANOL ( $\square)$

A partir da décima hora de fermentação ocorreu aumento significativo na velocidade de conversão de substrato em etanol. Torres Neto et al. (2006), estudando a elaboração de fermentado de caju, também observaram fase de adaptação do microrganismo ao meio em torno de 10 horas de fermentação, sendo a fase de maior consumo de substrato.

Para a produção de biomassa, o crescimento celular não foi tão pronunciado nas primeiras horas de fermentação. Entretanto, entre 10 e 27 horas de processo, o crescimento celular encontrou-se na fase exponencial, apresentando velocidade de crescimento elevada e células plenamente adaptadas ao meio.

$\mathrm{Na}$ Tabela 2 são apresentados os resultados do rendimento, produtividade, rendimento em produto $\left(Y_{p / s}\right)$, fator de conversão de substrato em biomassa $\left(Y_{x / s}\right)$ e velocidade específica de crescimento. Como a partir de $48 \mathrm{~h}$ de fermentação não ocorreram mais variações nas concentrações de substrato, produto e biomassa, esse foi o tempo utilizado para o cálculo da produtividade.

TABELA 2 - RENDIMENTO, PRODUTIVIDADE E PARÂMETROS CINÉTICOS DA FERMENTAÇÃO ALCOÓLICA DO VINHO DE MELANCIA

\begin{tabular}{ccccc}
\hline $\begin{array}{c}\text { Rendimento } \\
(\%)\end{array}$ & $\begin{array}{c}\text { Produtividade } \\
(\mathbf{g} / \mathbf{L} \cdot \mathbf{h})\end{array}$ & $Y_{P / S}$ & $\boldsymbol{Y}_{X / S}$ & $\begin{array}{c}\boldsymbol{\mu} \\
\left(\mathbf{h}^{-1}\right)\end{array}$ \\
\hline 94 & 1,65 & 0,65 & 0,14 & 0,028 \\
\hline
\end{tabular}

O rendimento e a produtividade apresentaram valores próximos aos encontrados por Almeida et al. (2006) quando estudaram a fermentação alcoólica do fruto do mandacaru e por Bortolini, Sant'Anna e Torres (2001) que obtiveram rendimentos de $75,6 \%$ a 92,4\% e produtividades de 
0,74 g/L'h a $2 \mathrm{~g} / \mathrm{L} \cdot \mathrm{h}$ na fermentação alcoólica do kiwi. Silva (2004) constatou rendimento em produto de $0,78 \mathrm{~g} / \mathrm{L} \cdot \mathrm{h}$ ao elaborar fermentado de caju. $O$ rendimento em produto, $Y_{P / S}$, obtido neste trabalho mostrou-se superior ao encontrado por Almeida et al. (2006) de 0,461 e Andrietta e Stupiello (1990) que observaram valor de $Y_{P / S}$ igual a 0,445 ao estudarem a fermentação alcoólica do caldo de cana. A velocidade específica de crescimento verificada foi inferior à obtida por Stroppa et al. (2009) e Ribeiro e Horii (1999) avaliando diferentes cepas de Saccharomyces cerevisiae para a fermentação de caldo de cana. No entanto, em ambos os casos, foi determinada a velocidade específica máxima de crescimento e não a velocidade específica de crescimento para dada concentração de substrato. As variações observadas nos parâmetros cinéticos de diversas pesquisas podem ser atribuídas a fatores como: cepa de levedura, operação do reator, temperatura e substrato, o que acarreta alterações no tempo de fermentação (ALMEIDA et al., 2006).

\section{CONCLUSÃO}

A produção do fermentado alcoólico de melancia mostrou-se tecnicamente viável. O produto estava de acordo com padrões determinados pela legislação vigente e com características semelhantes as de fermentados de outras frutas relatados na literatura. $O$ mosto permaneceu em fermentação por 20 dias, mas a partir de $48 \mathrm{~h}$ de processo não foram verificadas alterações nas concentrações de substrato, produto e biomassa. Os parâmetros da fermentação obtidos demonstram que a levedura comercial Saccharomyces cerevisiae apresentou bom desempenho no processo de fermentação alcoólica do suco de melancia, assemelhando-se ao observado para outros produtos. Mais estudos devem ser realizados para avaliar as características sensoriais e de aceitação do fermentado de melancia, a fim de confirmar a potencialidade do uso da melancia na elaboração de bebida alcoólica fermentada.

\section{ABSTRACT \\ ALCOHOLIC FERMENTATION KINETICS IN WATERMELON WINE PREPARATION}

The objective of this work was to produce a fermented watermelon beverage, compare its composition with standards in legislation and determine some kinetic parameters of fermentation. The process was performed in batch at $28 \pm 0.1^{\circ} \mathrm{C}$ for 20 days. The final product presented $\mathrm{pH}$, total titratable acidity, soluble solids content, alcohol content and total phenolic compounds, respectively equal to $4.1,4.45 \mathrm{~g} / \mathrm{L}, 6.0^{\circ} \mathrm{Brix}, 10 \% \mathrm{v} / \mathrm{v}$ and $677.73 \mathrm{mg} / \mathrm{L}$, in accordance to legal standards and similar to those reported in literature for other fermented beverages. From the kinetic study, it was found that after $48 \mathrm{~h}$ there were no variations in concentrations of substrate, product and biomass, respectively equal to $62.2 \mathrm{~g} / \mathrm{L}, 79.4 \mathrm{~g} / \mathrm{L}$ and $20.0 \mathrm{~g} / \mathrm{L}$. The yield was $94 \%$, productivity in the first $48 \mathrm{~h}$ was $1.65 \mathrm{~g} / \mathrm{L} \mathrm{h}$. Product yield (YP/S) was equal to 0.65 , the conversion factor of substrate in biomass (YX/S) was equal to 0.14 and the specific growth velocity was of $0.028 \mathrm{~h}^{-1}$. Production of the fermented watermelon beverage showed to be technically feasible, however, more studies about sensory and conservation aspects are needed to ensure safety of the product.

KEY-WORDS: WATERMELON WINE; PHENOLIC COMPOUNDS; ALCOHOLIC FERMENTATION.

\section{REFERÊNCIAS}

1 ALMEIDA, M.M.; TAVARES, D.P.S.A.; ROCHA, A.S.; OLIVEIRA, L.S.C.; SILVA, F.L.H.; MOTA, J.C. Cinética da produção do fermentado do fruto do mandacaru. Revista Brasileira de Produtos Agroindustriais, Campina Grande, v. 8, n. 1, p. $35-42,2006$

2 ANDRIETTA, S. R.; STUPIELLO, J. P. Simulação e modelagem para processo de fermentação alcoólica (II) contínua. Stab Açúcar, Álcool e subprodutos, Piracicaba, v. 9, p. 45-51, set./dez. 1990.

3 AQUARONE, E.; BORZANI, W.; SCHMIDELL, W.; LIMA, U.A.; HASHIZUME, T. Biotecnologia industrial: biotecnologia na produção de alimentos. São Paulo: Edgard Blücher, 2001. 523 p.

4 ASQUIERI, E.R.; CANDIDO, M.A.; DAMIANI, C.; ASSIS, E.M. Fabricación de vino blanco y tinto de jabuticaba (Mirciaria jaboticaba Berg) utilizando la pulpa y la cáscara respectivamente. Alimentaria, v. 355, n. 1, p. 97-109, 2004.

5 BORTOLINI, F.; SANT'ANNA, E.S.; TORRES, R.C. Comportamento das fermentações alcoólicas e acéticas de sucos 
de kiwi (Actinidia deliciosa); composição dos mostos e métodos de fermentação acética. Ciência e Tecnologia de Alimentos, Campinas, v. 21, n. 2, p. 236-243, maio/ago. 2001.

6 BORZANI, W.; LIMA, U. A.; AQUARONE, E. Engenharia bioquímica. 3. ed. São Paulo: Edgard Blücher, 1975.

7 BRASIL. Ministério da Agricultura, Pecuária e Abastecimento. Decreto n 2.314, de 04 de setembro de 1997. Regulamenta a Lei n. 8.918, de 14 de julho de 1994, que dispõe sobre a padronização, a classificação, o registro, a inspeção, a produção e a fiscalização de bebidas. Disponível em: <http://www.receita.fazenda.gov.br/legislacao/ Decretos/Ant2001/Ant1999/Dec231497.htm>.Acesso em:10/01/2011.

8 BRASIL. Ministrério da Agricultura, Pecuária e Abastecimento. Decreto nº 6.871, de 04 de junho de 2009. Regulamenta a Lei n. 8.918, de 14 de julho de 1994, que dispõe sobre a padronização, a classificação, o registro, a inspeção, a produção e a fiscalização de bebidas. Disponível em: <http://www.planalto.gov.br/ccivil_03/_Ato2007-2010/2009/Decreto/ D6871.htm> Acesso em: 10/01/2011.

9 CORAZZA, M. L.; RODRIGUES, D. G.; NOZAKI, J. Preparação e Caracterização do vinho de laranja. Química Nova, v. 24, n. 4, p. 449-452, ago. 2001.

10 DIAS, D. R.; SCHAWN, R. F.; LIMA, L. C. O. Metodologia para elaboração de fermentado de cajá (Spondias mombin L.). Ciência e Tecnologia de Alimentos, Campinas, v. 23 n. 3, p. 342, set./dez. 2003.

11 GAVA, A. J. Princípios de tecnologia de alimentos. 7. ed. São Paulo: Nobel, 1984. 284 p.

12 GOMES, P. Fruticultura brasileira. 13 ed. São Paulo: Nobel, 2007. 446 p.

13 INSTITUTO ADOLFO LUTZ. Métodos físicos-químicos para análise de alimentos. 4 ed. São Paulo, 2008. 1020 p.

14 IBGE. Instituto Brasileiro de Geografia e Estatística. Produção agrícola municipal - culturas temporárias e permanentes. Rio de Janeiro, 2010. v. 37.

$15 \mathrm{JOSHI}, \mathrm{V}$. K.; BHUTANI, V. P. The influence of enzymatic clarification in fermentation behavior and qualities of apple wine. Science des Aliments, v. n. 3, p. 491-498, 1991.

16 JOSHI, V. K.; SANDHU, D. K.; ATTRI, B. L.; WALLA, R. K. Cider preparation from apple juice concentrate and its consumer acceptability. Indian Journal of Horticulture, v. 48, p. 321-327, 1991.

17 LOPES, R. V. V.; SILVA, F. L. H.; Elaboração de fermentados a partir do figo-da-india. Revista de Biologia e Ciências da Terra, v. 6, n. 2, p. 305-315, 2006.

18 MUNIZ, C. R.; BORGES, M. F.; ABREU, F. A. P.; NASSU, R. T.; FREITAS, C. A. S. Bebidas fermentadas a partir de frutos tropicais. Boletim do CEPPA, v. 20, n. 2, p. 309-322, jul./dez. 2002.

19 OURA, E. Reaction products of yeast fermentations. Process Biochemistry, v. 12, n. 3, p. 19-21, 35, 1977.

20 PELTER, M. W.; MCQUADE, J. Brewing science in the chemistry laboratory: a mashing investigation of starch and carbohydrates. J. Chem. Educ., v. 82, p.1811-1812, 2005.

21 REDDY, L. V. A.; REDDY, O. V. S. Production and characterization of wine from mango fruit (Mangifera indica $L$ ). World Journal of Microbiology \& Biotechnology, Oxford, v. 21, n. 8-9, p. 1345-1350, Dec. 2005

22 RIBEIRO, C. A. F.; HORII, J. Potencialidades de linhagens de levedura Saccharomyces cerevisiae para a fermentação do caldo de cana. Scientia Agricola, Piracicaba, v. 56, n. 2, p. 255-263, 1999.

23 RIZZON, L. A.; MANFROI, V.; MENEGUZZO, J. Elaboração de suco de uva na pequena propriedade vitícola. Bento Gonçalves: EMBRAPA-CNPUV, 1998. 24 p.

24 SHAHIDI, F; NACZK, M. Antioxidant properties of food phenolics. In: SHAHIDI, F; NACZK, M. (Eds.). Food phenolics: sources, chemistry, effects and applications. Lancaster: Technomic Publishing, 1995. 235 p.

25 SILVA, M.E. Estudos cinéticos da fermentação alcoólica da produção de vinho e da fermentação acética de produção de vinagre de vinho de caju. 2004. 137 f. Dissertação (Mestrado em Engenharia Química), Universidade Federal de Campina Grande, Campina Grande, 2004.

26 StRopPA, C. T.; ALVES, J. G. L. F.; FIgUeIREDO, A. L. F.; CASTRO, C. C. Parâmetros cinéticos de linhagens de levedura isoladas de alambiques mineiros. Ciência e Agrotecnologia, Lavras, v. 33, p. 1978-1983, 2009.

27 TORRES NETO, A B.; SILVA, M. E.; SILVA, W. B.; SWARNAKAR, R.; SILVA, F. L. H. Cinética e caracterização físico-química do fermentado do pseudofruto do caju (Anacardium occidentale L.). Química Nova, v. 29, n. 3, p. 489-492, maio/jun. 2006.

28 USENIK, V.; FABCIC, J.; STAMPAR, F. Sugars, organic acids, phenolic composition and antioxidant activity of sweet cherry (Prunus avium L.). Food Chemistry, v. 107, p. 185-192, 2008. 
BORZANI, W.; LIMA, U. A.; AQUARONE, E. Engenharia bioquímica. 3. ed. São Paulo: Edgard Blücher, 1975.

7 BRASIL. Ministério da Agricultura, Pecuária e Abastecimento. Decreto $\mathrm{n}^{\circ}$ 2.314, de 04 de setembro de 1997. Regulamenta a Lei $\mathrm{n}$. 8.918, de 14 de julho de 1994, que dispõe sobre a padronização, a classificação, o registro, a inspeção, a produção e a fiscalização de bebidas. Disponível em: <http://www. receita.fazenda.gov.br/legislacao/Decretos/Ant2001/Ant1999/Dec231497.htm>.Acessoem:10/01/2011.

8 BRASIL. Ministrério da Agricultura, Pecuária e Abastecimento. Decreto n 6.871, de 04 de junho de 2009. Regulamenta a Lei n. 8.918, de 14 de julho de 1994, que dispõe sobre a padronização, a classificação, o registro, a inspeção, a produção e a fiscalização de bebidas. Disponível em: <http://www.planalto.gov.br/ccivil 03/Ato2007-2010/2009/Decreto/ D6871.htm> Acesso em: 10/01/2011.

9 CORAZZA, M. L.; RODRIGUES, D. G.; NOZAKI, J. Preparação e Caracterização do vinho de laranja. Química Nova, v. 24, n. 4, p. 449-452, ago. 2001.

10 DIAS, D. R.; SCHAWN, R. F.; LIMA, L. C. O. Metodologia para elaboração de fermentado de cajá (Spondias mombin L.). Ciência e Tecnologia de Alimentos, Campinas, v. 23 n. 3, p. 342, set./dez. 2003.

11 GAVA, A. J. Princípios de tecnologia de alimentos. 7. ed. São Paulo: Nobel, 1984. 284 p.

12 GOMES, P. Fruticultura brasileira. 13 ed. São Paulo: Nobel, 2007. 446 p.

13 INSTITUTO ADOLFO LUTZ. Métodos físicos-químicos para análise de alimentos. 4 ed. São Paulo, 2008. 1020 p.

14 IBGE. Instituto Brasileiro de Geografia e Estatística. Produção agrícola municipal - culturas temporárias e permanentes. Rio de Janeiro, 2010. v. 37.

$15 \mathrm{JOSHI}, \mathrm{V}$. K.; BHUTANI, V. P. The influence of enzymatic clarification in fermentation behavior and qualities of apple wine. Science des Aliments, v. n. 3, p. 491-498, 1991

16 JOSHI, V. K.; SANDHU, D. K.; ATTRI, B. L.; WALLA, R. K. Cider preparation from apple juice concentrate and its consumer acceptability. Indian Journal of Horticulture, v. 48, p. 321-327, 1991.

17 LOPES, R. V. V.; SILVA, F. L. H.; Elaboração de fermentados a partir do figo-da-india. Revista de Biologia e Ciências da Terra, v. 6, n. 2, p. 305-315, 2006

18 MUNIZ, C. R.; BORGES, M. F.; ABREU, F. A. P.; NASSU, R. T.; FREITAS, C. A. S. Bebidas fermentadas a partir de frutos tropicais. Boletim do CEPPA, v. 20, n. 2, p. 309-322, jul./dez. 2002.

19 OURA, E. Reaction products of yeast fermentations. Process Biochemistry, v. 12, n. 3, p. 19-21, 35, 1977.

20 PELTER, M. W.; MCQUADE, J. Brewing science in the chemistry laboratory: a mashing investigation of starch and carbohydrates. J. Chem. Educ., v. 82, p.1811-1812, 2005.

21 REDDY, L. V. A.; REDDY, O. V. S. Production and characterization of wine from mango fruit (Mangifera indica $L$ ). World Journal of Microbiology \& Biotechnology, Oxford, v. 21, n. 8-9, p. 1345-1350, Dec. 2005

22 RIBEIRO, C. A. F.; HORII, J. Potencialidades de linhagens de levedura Saccharomyces cerevisiae para a fermentação do caldo de cana. Scientia Agricola, Piracicaba, v. 56, n. 2, p. 255-263, 1999.

23 RIZZON, L. A.; MANFROI, V.; MENEGUZZO, J. Elaboração de suco de uva na pequena propriedade vitícola. Bento Gonçalves: EMBRAPA-CNPUV, 1998. 24 p.

24 SHAHIDI, F; NACZK, M. Antioxidant properties of food phenolics. In: SHAHIDI, F; NACZK, M. (Eds.). Food phenolics: sources, chemistry, effects and applications. Lancaster: Technomic Publishing, 1995. 235 p.

25 SILVA, M.E. Estudos cinéticos da fermentação alcoólica da produção de vinho e da fermentação acética de produção de vinagre de vinho de caju. 2004. 137 f. Dissertação (Mestrado em Engenharia Química), Universidade Federal de Campina Grande, Campina Grande, 2004.

26 STROPPA, C. T.; ALVES, J. G. L. F.; FIGUEIREDO, A. L. F.; CASTRO, C. C. Parâmetros cinéticos de linhagens de levedura isoladas de alambiques mineiros. Ciência e Agrotecnologia, Lavras, v. 33, p. 1978-1983, 2009.

27 TORRES NETO, A B.; SILVA, M. E.; SILVA, W. B.; SWARNAKAR, R.; SILVA, F. L. H. Cinética e caracterização físico-química do fermentado do pseudofruto do caju (Anacardium occidentale L.). Química Nova, v. 29, n. 3, p. 489-492, maio/jun. 2006.

28 USENIK, V.; FABCIC, J.; STAMPAR, F. Sugars, organic acids, phenolic composition and antioxidant activity of sweet cherry (Prunus avium L.). Food Chemistry, v. 107, p. 185-192, 2008. 